\title{
Add-on Trial of Clobazam in Intractable Adult Epilepsy with Plasma Level Correlations
}

\author{
A. Guberman, M. Couture, K. Blaschuk and A. Sherwin
}

\begin{abstract}
Clobazam, a novel benzodiazepine, was used as an add-on agent in 47 adult patients with intractable epilepsy and a variety of seizure types. A $>75 \%$ reduction in seizure frequency was observed in $42 \%$ (18) of the patients and a $>50 \%$ reduction in $65 \%$ (29) of the patients which was sustained over a mean follow-up period of 13.3 $( \pm 5.6)$ months. Nine patients had to discontinue the drug due to minor adverse effects or increased seizures. Possible tolerance developed in 6 patients. Plasma levels of the active metabolite $\mathrm{N}$-desmethylclobazam were linearly related to dosage and appeared to correlate with both therapeutic and toxic responses. Clobazam appears to be a safe and effective add-on antiepileptic for a wide variety of seizure types in intractable epilepsy.

RÉSUMÉ: Essai thérapeutique avec corrélation des niveaux plasmatiques du clobazam comme traitement d'appoint dans l'épilepsie réfractaire de l'adulte Le clobazam, une nouvelle benzodiazépine, a été utilisé comme traitement d'appoint chez 47 adultes présentant une épilepsie réfractaire et des crises de types variés. Une diminution de plus de $75 \%$ de la fréquence des crises a été observée chez $42 \%$ (18) des patients et une diminution de plus de $50 \%$ chez $65 \%$ (29), diminution maintenue sur une période de suivi moyenne de $13.3( \pm 5.6)$ mois. Neuf patients ont dû cesser la médication à cause d'effets secondaires mineurs ou d'une augmentation des crises. Il est possible qu'une tolérance se soit développée chez 6 patients. Les niveaux plasmatiques du métabolite actif, le N-desmethylclobazam, étaient en relation linéaire avec la dose et semblaient corréler avec la réponse thérapeutique et la toxicité. Le clobazam semble être un agent antiépileptique d'appoint sécuritaire et efficace dans une grande variété de types de convulsions dans l'épilepsie réfractaire.
\end{abstract}

Can. J. Neurol. Sci. 1990; 17:311-316

Clobazam (Frisium $(\circledR)$ is a 1,5 -benzodiazepine as opposed to other marketed benzodiazepines which have nitrogen atoms located at the 1,4 position of the $B$ ring and an amine group in positions 4 and 5 . The drug was first introduced in Europe as a relatively non-sedating anxiolytic in 1975 . Gastaut, in 1978 reported clobazam to be an effective add-on antiepileptic drug in man, ' an observation subsequently confirmed by several open and double-blind placebo-controlled studies. ${ }^{2-4}$ The present study is an analysis of 47 therapy-resistant adult epilepsy patients in whom clobazam was used as an add-on agent with blood-level correlations.

\section{METHODS}

\section{Patient Population}

Forty-seven consecutive adult patients with uncontrolled epilepsy previously followed at the Ottawa General Hospital Epilepsy Clinic for 6 months to 12 years (mean: 4 years), were started on clobazam. Patients with progressive brain lesions, recent $(<1$ yr) epilepsy surgery, or with a history of non-compliance were excluded. Characteristics of the population are presented in Table 1 . Only 4 patients were mentally retarded, all with
Lennox-Gastaut syndrome. Thirty patients had complex partial seizures, 27 of whom had generalized tonic-clonic seizures in addition. Thirty-nine patients had generalized tonic-clonic seizures with other seizures as well in all but six patients. All patients were longstanding, proven epileptic patients who had been resistant or intolerant to optimal doses of several anti-

\begin{tabular}{|c|c|}
\hline \multicolumn{2}{|l|}{$\mathrm{N}=47$} \\
\hline \multicolumn{2}{|l|}{ Mean age: 35 yr (20-71 yr) } \\
\hline \multicolumn{2}{|l|}{ Mean duration of epilepsy: 19 yr (3-61 yr) } \\
\hline Mean time followed in clinic before entry into trial: & $4 \mathrm{yr}$ \\
\hline \multicolumn{2}{|l|}{ Seizure types: } \\
\hline Generalized tonic-clonic with other seizures & 33 \\
\hline Generalized tonic-clonic alone & 6 \\
\hline $\begin{array}{c}\text { Complex partial }+ \text { generalized tonic-clonic } \\
\pm \text { other seizures }\end{array}$ & 27 \\
\hline Complex partial alone & 3 \\
\hline Variety of mixed seizures (absences, myoclonic tonic, etc.) & 7 \\
\hline Lennox-Gastaut & 4 \\
\hline
\end{tabular}

From the Division of Neurology (A.G., M.C.), Ottawa General Hospital, Ottawa and the Montreal Neurological Institute (K.B., A.S.), Montreal Received January 23, 1990. Accepted April 13, 1990

Reprint requests to: Dr. A. Guberman, Division of Neurology, Ottawa General Hospital, 501 Smyth Road, Ottawa, Ontario, Canada K IH 8L6 
Table 2. Characteristics of Groups Divided by Response to Clobazam in 43 Patients Followed for Over 3 Months

\begin{tabular}{|c|c|c|c|c|}
\hline & Group A & Group B & Group C & Group D \\
\hline & $\begin{array}{l}\text { (complete } \\
\text { control) }\end{array}$ & $\begin{array}{l}(>75 \% \text { seizure } \\
\text { reduction) }\end{array}$ & $\begin{array}{l}(50-75 \% \text { seizure } \\
\text { reduction) }\end{array}$ & $\begin{array}{l}(<50 \% \text { seizure } \\
\text { reduction) }\end{array}$ \\
\hline $\mathrm{N}$ & 7 & 11 & 12 & 13 \\
\hline Mean follow-up (mo) & $13.3 \pm 4.7$ & $13.5 \pm 5.8$ & $13.2 \pm 5.9$ & $8.4 \pm 5.5$ \\
\hline Mean daily dose (mg) & 26 & 37.6 & 37.9 & 40.4 \\
\hline Mean duration of epilepsy (yr) & 22.1 & 15.8 & 20.4 & 22 \\
\hline \multicolumn{5}{|l|}{ Seizure types: } \\
\hline $\begin{array}{l}\text { GTC + CPS } \\
\text { GTC + ABS } \\
\text { GTC } \\
\text { GTC + CPS + OTHER } \\
\text { CPS } \\
\text { ABS + NGS }\end{array}$ & $\begin{array}{l}4 \\
1 \\
2\end{array}$ & $\begin{array}{l}6 \\
1 \\
3 \\
1\end{array}$ & $\begin{array}{l}7 \\
2 \\
3\end{array}$ & $\begin{array}{l}3 \\
1 \\
1 \\
5 \\
2 \\
1\end{array}$ \\
\hline $\begin{array}{l}\text { LENNOX-GASTAUT } \\
\text { (also included in seizure types above) }\end{array}$ & & 2 & 1 & 1 \\
\hline \multicolumn{5}{|l|}{ Other concurrent antiepileptic drugs: } \\
\hline $\begin{array}{l}\text { Carbamazepine } \\
\text { Phenytoin } \\
\text { Valproic acid } \\
\text { Ethosuximide } \\
\text { Primidone }\end{array}$ & $\begin{array}{l}5 \\
4 \\
2\end{array}$ & $\begin{array}{l}9 \\
3 \\
3 \\
1\end{array}$ & $\begin{array}{l}5 \\
7 \\
4 \\
1 \\
1\end{array}$ & $\begin{array}{l}6 \\
1 \\
6 \\
2\end{array}$ \\
\hline
\end{tabular}

Key: CPS=complex partial seizure GTC=generalized tonic-clonic seizure

ABS=absence seizure $\quad$ NGS=nonconvulsive generalized status epilepticus

epileptics used alone or in combination. Seizure frequency was determined for the 6 months prior to entry from clinic records, review of seizure calendars and re-questioning of the patients and their families. All but one patient had at least one seizure per month, 17 had 1-several seizures per day, 16 had 5-30 per month and 13 had 1-4 per month. Seven patients had undergone previous epilepsy surgery: temporal lobectomy (5), frontal resection (1) and corpus callosotomy (1).

The mean number of other concurrent antiepileptic drugs used by our patient population was 1.3 (Table 2). Five patients eventually were maintained on clobazam monotherapy.

\section{Clobazam Dosage and Outcome Measures}

Clobazam was added to previous antiepileptic drug therapy starting with $10 \mathrm{mg}$ at bedtime then increased by $10 \mathrm{mg}$ every five days to reach a dosage of $60 \mathrm{mg}$ per day $(20 \mathrm{mg}$ QAM, $40 \mathrm{mg}$ QHS) as tolerated. Patients were required to record seizures on a special calendar and were seen initially at 2-month intervals. At each visit, BUN, AST, ALT, bilirubin, alkaline phosphatase, T4 and CBC were determined. Serum levels of concurrent anti-epileptic drugs were measured by an immunofluorescent method prior to beginning and at each follow-up visit. Plasma levels of clobazam and its active metabolite $\mathrm{N}$ desmethylclobazam were determined in 39 patients by a modified liquid chromatographic method. 5

\section{RESULTS}

Forty-three patients received clobazam for more than 3 months based on response of major seizure types, seizure outcome in this group was recorded at each follow-up visit as fol- lows: group A, complete control; group B, greater than $75 \%$ seizure reduction; group $\mathrm{C}, 50-75 \%$ seizure reduction; and group D, less than $50 \%$ seizure reduction. Forty-two percent of our patients had an excellent response to the drug $(75 \%$ or greater seizure reduction) and an additional $28 \%$ had a $50-75 \%$ seizure reduction. Analysis of response at the most recent followup visit according to seizure type is shown in Figure 1. The characteristics of each response group, including length of followup, are shown in Table 2. Mean follow-up in the three responding groups was 13.3 months with a range of 3-24 months. Secondarily generalized seizures responded best while myoclonic and atonic seizures responded less well in the small number of patients represented.

Five patients who discontinued their other antiepileptics soon after starting clobazam and remained on monotherapy were followed for a mean of 17 months (mean dose $60 \mathrm{mg}$ per day). Two of these 5 patients fell into group $\mathrm{C}$ with good response and the other 3 were nonresponders but chose to remain on the drug. In groups $\mathrm{A}, \mathrm{B}$, and $\mathrm{C}$ with excellent or good response, five patients had previously failed on clonazepam and four on nitrazepam. Two of the patients previously not responding to clonazepam were completely controlled on clobazam. Of the 7 patients with previous epilepsy surgery 4 fell into group B and 1 into group $\mathrm{C}$.

We compared best response within the first 3 months to final response. In only 6 patients was there a suggestion of escape from initial excellent control. Complex partial seizures were more likely to recur than generalized tonic-clonic seizures. Four of these patients still show nearly complete control of seizures. Complex partial seizures were more likely to recur than generalized tonic-clonic seizures. All six patients remained on the drug 


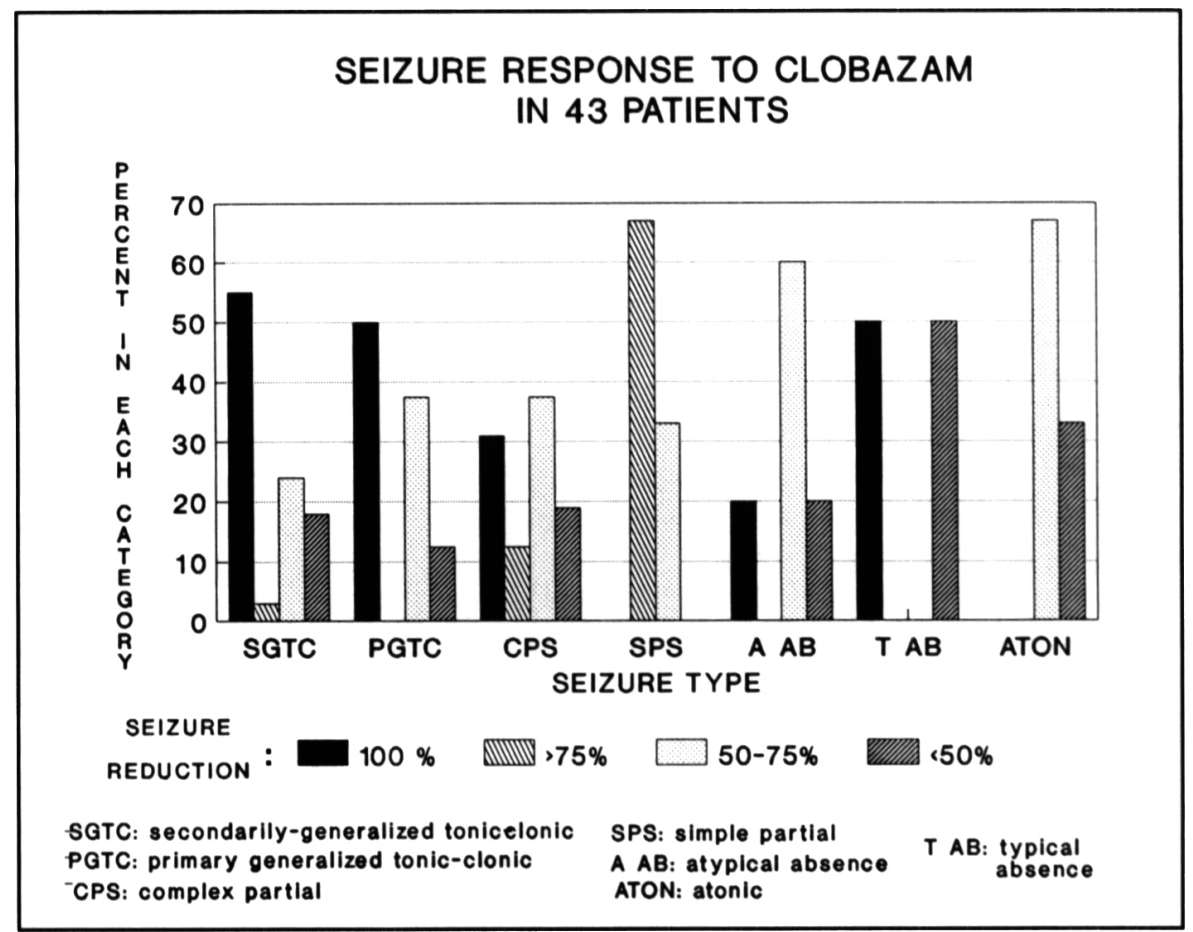

Figure I - Response to clobazam according to seizure type. Small mumbers of patients were seen with the last 4 seizure types.

and continued to derive at least some reduction in seizure frequency and/or severity.

Clobazam and $\mathrm{N}$-desmethylclobazam plasma levels in 17 patients with excellent control (groups A and B) are shown plotted against daily dose in $\mathrm{mg} / \mathrm{kg} / \mathrm{day}$ in Figure 2 . There was a good linear relation between daily dose and plasma level for both the parent drug $(r=0.94)$ and its metabolite $(r=0.99)$. $\mathrm{N}$ desmethylclobazam/clobazam plasma level ratio was approximately 10:1. Ratios were generally higher in patients on concurrent therapy with carbamazepine or phenytoin than with either sodium valproate or clobazam monotherapy. The 6 patients with dose-related toxicity (mainly fatigue) all had $\mathrm{N}$-desmethylclobazam levels greater than $9 \mu \mathrm{mol} / \mathrm{L}$. The correlation between toxicity and clobazam levels was less clear-cut. The therapeutic range was not clearly defined in our study but the upper limits of $1 \mu \mathrm{mol} / \mathrm{L}$ for clobazam and $10 \mu \mathrm{mol} / \mathrm{L}$ for $\mathrm{N}$-desmethylclobazam appeared to be fair approximations. Serum levels of concurrent anti-epileptic drugs were not significantly altered by clobazam except in two cases where serum phenytoin levels were significantly elevated into the toxic range within days of starting clobazam. Phenytoin levels fell once the clobazam dose was reduced.

Clobazam had to be discontinued in 13 of the 47 patients due to side effects in 7 cases (mean dose of $18.5 \mathrm{mg} /$ day), increased seizures in 2 cases and lack of efficacy in 4 cases.

The overall incidence of side effects, the vast majority of which were transient and well tolerated, was $85 \%$ (Table 3 ). Many of these side effects were confined to the initial stages of therapy when the dosage was increased to $60 \mathrm{mg} /$ day but resolved with reduction of dosage. Drowsiness was seen in 31/47 cases but persisted in only 6 cases and in no instance necessitated ces- sation of therapy. Ataxia, dizziness and blurred vision were also common initially. No case showed abnormalities of liver function tests, BUN, electrolytes, CBC or T4 attributable to clobazam. No serious side effects were encountered.

Table 3. Side Effects in 40/47 Patients

\begin{tabular}{lcc}
\hline \hline Side Effect & N & $\begin{array}{c}\text { Mean Dose } \\
\text { (mg/day) }\end{array}$ \\
\hline Drowsiness $\quad 31$ & 34 \\
$\quad$ - persistent & 6 & \\
Ataxia & 0 & \\
Blurred vision & $15(1)^{*}$ & 28 \\
Dizziness & 10 & 26 \\
Emotional lability & 7 & 46 \\
Irritability/aggressiveness & $6(4)$ & 38 \\
Depression or worsening depression & 5 & 36 \\
Weight gain & $3(1)$ & 50 \\
Decreased memory & 2 & 45 \\
Impotence & 2 & 60 \\
Increased libido & 2 & 35 \\
Decreased libido & 2 & 13.5 \\
Bad dreams & 1 & 40 \\
Weight loss & 1 & 50 \\
Decreased appetite & 1 & 30 \\
Vesicular stomatitis & 1 & 10 \\
Increased seizures & $1(1)$ & 10 \\
\hline
\end{tabular}

* Numbers in parentheses refer to patients in whom the side effects necessitated discontinuation of clobazam 


\section{CLOBAZAM PLASMA LEVELS VS DOSE} 17 Patients with Excellent Response *

CLOBAZAM LEVEL (micromol/L)

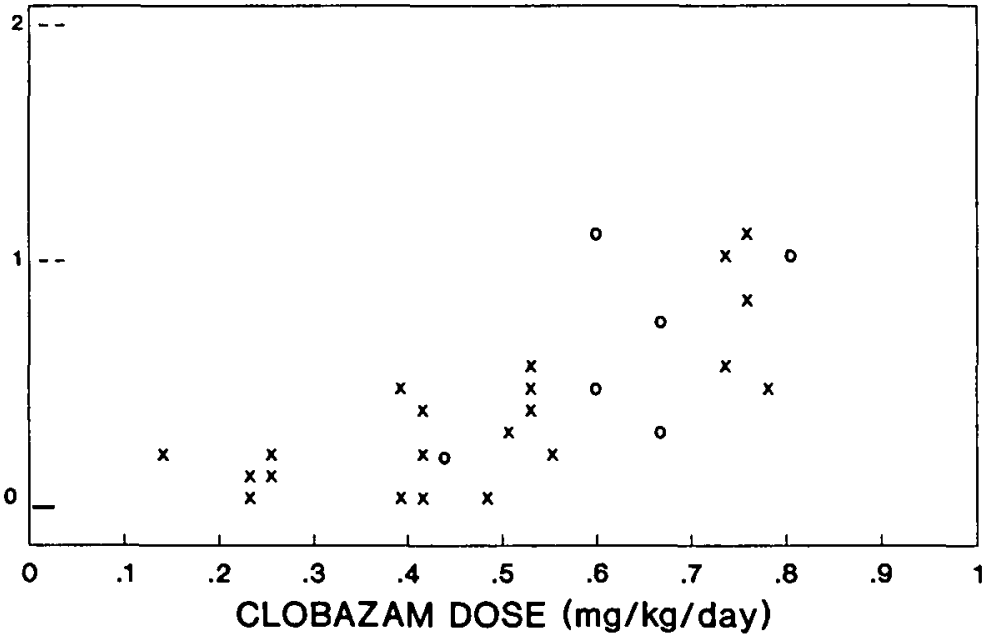

A

clrcles represent patlents with toxicity (fatlgue;atsxla)

\section{N-DESMETHYLCLOBAZAM LEVELS VS DOSE 17 Patients with Excellent Response}

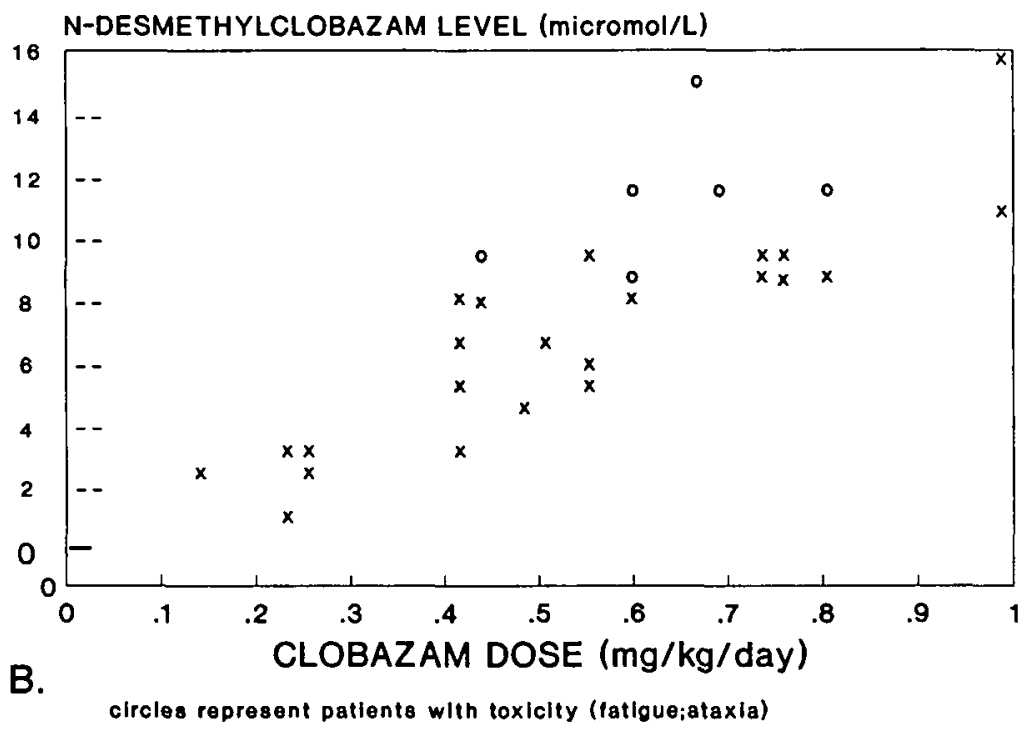

Figure 2 - Clobazam (A) and N-desmethylclobazam (B) plasma levels compared to dose in patients with an excellent response. Both clobazam and N-desmethylclobazam levels showed a good correlation with dose but levels of the metabolite were a better indicator of dose-related toxicity. 


\section{Discussion}

In our open add-on trial, $42 \%$ of 43 patients remaining on clobazam for over 3 months had an excellent response (all still on the drug) and $70 \%$ had a good or excellent response $(87 \%$ still on the drug) with a mean follow-up of 14 months. These response rates are impressive in view of the fact that the drug was used in chronic, intractable patients who had failed all previous medical (or surgical) therapy including other benzodiazepines in 7 cases. Furthermore, in analyzing results, borderline responses were always relegated to a lower category and calculations were done on the basis of all major seizure types for each patient. Although the study was not conducted in a double-blind fashion, placebo effect was felt to be minimal since all patients were previously well-known to the clinic, had been tried on multiple drugs without response and patients were seen during their clinic visits in the usual fashion during the study. These response rates are comparable to the $41.6 \%$ positive response rates reported by Koeppen ${ }^{2}$ in his review of 18 open studies involving 793 patients with similar seizure types to our patients. In 9 open studies lasting at least 12 months reviewed by Robertson, ${ }^{3}$ the mean percent improvement was $65 \%$, almost identical to our results. However there was some variability among studies in criteria for improvement and it is difficult to discern from these studies how many of the responders were able to remain on the drug and did not develop tolerance to the beneficial effects.

In a multi-centre European placebo-controlled add-on crossover study ${ }^{4}$ in complex partial seizures, $19 \%$ of patients became seizure-free on clobazam versus none on placebo. In Schmidt's 8 separate analysis of his 20 patients, $40 \%$ of patients had greater than $75 \%$ seizure reduction. The short duration (less than 3 months) of treatment somewhat limits the interpretation of these results.

Clobazam appears to suppress a wide variety of seizures and is particularly effective in secondarily generalized tonic-clonic and complex partial seizures. It has been found effective in alcohol withdrawal seizures, ${ }^{7}$ catamenial epilepsy ${ }^{8}$ (used intermittently), eating epilepsy, ${ }^{8}$ convulsive status epilepticus, ${ }^{10}$ nonconvulsive generalized status epilepticus, ${ }^{11}$ startle-induced epilepsy" and stress-sensitive seizures. ${ }^{12}$

The vast majority of previous studies have employed clobazam as an add-on agent, usually with carbamazepine or phenytoin, and therefore its efficacy in monotherapy is still unknown. However, clobazam monotherapy was found to be very effective in 39 pediatric patients, mainly with partial seizures. 13,14

Side effects in our patients and in the literature, although seen in more than $1 / 3$ of patients, ${ }^{2,3}$ usually consist of mild drowsiness, ataxia or dizziness related to dose and the initiation of treatment. In only a very small proportion of patients are side effects severe enough to require discontinuation of treatment. Reversible vesicular stomatitis in one patient was the most serious side effect seen in our series and no serious side effects have been noted in the literature. It has been noted that clobazam shows less impairment of cognitive function and psychomotor performance than the 1,4 benzodiazepines both clinically and experimentally.2,14,16 Positive psychotropic, particularly anxiolytic, effects were noted by some of our patients.

In our series tolerance possibly appeared in $6 / 43$ patients but $4 / 6$ remained on the drug with excellent control and in 1 case escape was related to a reduction in dosage due to side effects. This is substantially less than the figures mentioned by most other authors which generally run between $30-40 \% .3,6.17 .18$ In other studies tolerance has been somewhat variably defined and without plasma level measurements, falling blood levels could not be ruled out as a cause for escape from control. However, once tolerance develops, increases in dose do not restore seizurc control and often produce sedation. ${ }^{18}$ Gastaut and Low 20 in 1979 found tolerance in one-third of their patients, usually within the first three months. In a later long-term study (3-5.7 years), Gastaut et al 10 noted that once clobazam was effective for several months, efficacy tended to be maintained for several years. Rosenberg et al 21 have shown that clobazam produces especially rapid tolerance as compared to clonazepam or diazepam when used in amygdala-kindled rats. The explanation for the wide variability in the incidence of tolerance in clinical studies and the mechanism of development of tolerance will need further study before this important issue can be resolved.

Plasma levels in our patients were quite variable although the levels in controlled patients were usually between $0.1-1.1 \mu \mathrm{mol} / \mathrm{L}$ for clobazam and $2-10 \mu \mathrm{mol} / \mathrm{L}$ for the $\mathrm{N}$-desmethyl metabolite. The indefinite relationship between plasma levels and efficacy has been previously noted. 19 The $\mathrm{N}$-desmethyl metabolite bore a closer correlation to dose than did the parent drug and also to the development of drug toxicity. It is interesting that all 6 patients with dose-related drug toxicity had $\mathrm{N}$-desmethylclobazam levels over $9 \mu \mathrm{mol} / \mathrm{L}$.

Clobazam has many desirable characteristics as an antiepileptic agent. The parent drug and active metabolite have relatively long half lives (mean $18 \mathrm{hr}$ and $42 \mathrm{hr}$ respectively ${ }^{19}$ ) allowing for twice or perhaps single daily dosing. It is well-tolerated by most patients and there appears to be a low incidence of serious side effects. Its anxiolytic properties may be useful in many epileptic patients. The drug appears to be very effective in at least one-third of intractable seizure patients. Its antiepileptic spectrum is quite broad. The development of tolerance in adults may be less frequent than originally suspected.

A number of unanswered questions remain. The incidence of tolerance and whether its development can be forestalled by specific dosing regimens need to be explored. The efficacy of clobazam in monotherapy remains unknown. The effects of clobazam on cognition relative to other anti-epileptic drugs needs further study. At the present time it can be stated that clobazam shows a great deal of promise as an add-on agent in a variety of intractable seizure types and will likely become the benzodiazepine of choice for chronic treatment.

\section{ACKNOWLEDGEMENT}

Thanks are due to Hoechst Canada for generously supplying all the clobazam (Frisium $($ ) and analytical standards used in this study. We are also grateful to Ms. Johanne Robitaille for technical assistance and Ms. Claire Loyer for her help in preparing the manuscript.

\section{REFERENCES}

1. Gastaut H. Propriétés antiépileptiques exceptionelles et méconnues d'un anxiolytique du commerce, le clobazam. Concours Med 1978; 100: 3697-3701.

2. Koeppen D. A review of clobazam studies in epilepsy. $\ln$ : Hindmarch I, Stonier PD, Trimble MR, eds. Human Psychopharmacology and Clinical Applications. International Congress 
and Symposium Series, No. 74. London: Royal Society of Medicine 1985: 207-215.

3. Robertson MM. Current status of the 1,4- and 1,5-benzodiazepines in the treatment of epilepsy: the place of clobazam. Epilepsia 1986; 27 (Suppl 1): S27-S41.

4. Koeppen D, Baruzzi A, Copozza M, et al. Clobazam in therapyresistant patients with partial epilepsy: a double-blind placebocontrolled crossover study. Epilepsia 1987; 28: 495-506.

5. Heazlewood RL and Lemass RWJ. Simple high-performance liquid chromatographic assay for the routine monitoring of clonazepam in plasma. J Chromatogr 1984 ; 336-229-233.

6. Schmidt D, Rohde $M$, Wolf $P$, et al. Clobazam for refractory focal epilepsy. A controlled trial. Arch Neurol 1986; 43: 824826.

7. Franceschi M, Ferini-Strambi L, Mastrangelo M, et al. Clobazam in drug-resistant and alcoholic withdrawal seizures. Clin Trials J 1983; 20: 119-125.

8. Feely M, Gibson J. Intermittent clobazam for catamenial epilepsy: avoid tolerance. J Neurol Neurosurg Psychiatry 1984; 47: [279-I 282.

9. Aguglia U, Tinuper P. Eating seizures. Eur Neurol 1983; 22 227-231.

10. Gastaut $\mathrm{H}$, Tinuper $\mathrm{P}$, Aguglia $\mathrm{U}$, et al. Traitement de certains états de mal par ingestion d'une dose unique de clobazam. Rev EEG Neurophysiol 1984; 14: 203-206.

11. Tinuper P, Aguglia $U$, Gestaut $H$. Use of clobazam in certain forms of status epilepticus and in startle-induced epileptic seizures. Epilepsia 1986; 27 (Suppl 1): S18-S26.

12. Scott DF, Moffett A. On the anticonvulsant and psychotropic properties of clobazam - a preliminary study. Epilepsia 1986; 27(Suppl 1): S42-S44.
13. Dulac D, Figueroa D, Rey E, et al. Monothérapie par le clobazam dans les épilepsies de l'enfant. Presse Med 1983; 12: 10671069.

14. Plouin P, Jalin C. EEG changes in epileptic children treated with clobazam as monotherapy. In: Hindmarch I, Stonier PD, Trimble MR, eds. Human Psychopharmacology and Clinical Applications. International Congress and Symposium Series, No. 74, London: Royal Society of Medicine 1985; 191-197.

15. Cull CA, Trimble MR. Anticonvulsant benzodiazepines and performance. In: Hindmarch I, Stonier PD, Trimble MR, eds. Human Psychopharmacology and Clinical Applications. International Congress and Symposium Series, No. 74, London: Royal Society of Medicine 1985; 121-128.

16. Simon P. Comparative study in mice of ten 1,4-benzodiazepines and of clobazam: anticonvulsant, anxiolytic, sedative, and myorelaxant effects. Epilepsia 1986; 27 (Suppl 1): S14-S17.

17. Martin AA. The antiepileptic effects of clobazam: a long-term study in resistant epilepsy. In: Hindmarch I, Stonier PD, eds. Clobazam. International Congress and Symposium Series, No. 43. London: Royal Society of Medicine 1981; $151-157$.

18. Callaghan N, Goggin T. Adjunctive therapy in resistant epilepsy. Epilepsia 1988; 29 (Suppl 1): S29-S35.

19. Shorvon SD. Benzodiazepines. Clobazam. In: Levy R, Mattson R, Meldrum B, Penry JK, Dreifuss FE, eds. Antiepileptic Drugs, 3rd ed. New York: Raven Press 1989; chapter 59.

20. Gastaut H, Low MD. Antiepileptic properties of clobazam, a 1,5 benzodiazepine, in man. Epilepsia 1979; 20: 437-446.

21. Rosenberg HC, Tietz EI, Chiu TH. Tolerance to anticonvulsant effects of diazepam, clonazepam, and clobazam in amygdalakindled rats. Epilepsia 1989; 30: 276-285. 